(C) 2013 IEEE. Personal use of this material is permitted. Permission from IEEE must be obtained for all other uses, in any current or future media, including reprinting/republishing this material for advertising or promotional purposes, creating new collective works, for resale or redistribution to servers or lists, or reuse of any copyrighted component of this work in other works. 


\title{
Methodologies to Determine Operating Reserves due to Increased Wind Power
}

\author{
Hannele Holttinen (Member IEEE), Michael Milligan (Senior Member IEEE), Erik Ela (Member \\ IEEE), Nickie Menemenlis, Jan Dobschinski, Barry Rawn (Member IEEE), Ricardo J. Bessa, Damian \\ Flynn (Senior Member IEEE), Emilio Gomez Lazaro (Member IEEE), Nina Detlefsen
}

\begin{abstract}
Power systems with high wind penetration experience increased variability and uncertainty, such that determination of the required additional operating reserve is attracting a significant amount of attention and research. This paper presents methods used in recent wind integration analyses and operating practice, with key results that compare different methods or data. Wind integration analysis over the past several years has shown that wind variability need not be seen as a contingency event. The impact of wind will be seen in the reserves for non-event operation (normal operation dealing with deviations from schedules). Wind power will also result in some events of larger variability and large forecast errors that could be categorized as slow events. The level of operating reserve that is induced by wind is not constant during all hours of the year, so that dynamic allocation of reserves will reduce the amount of reserves needed in the system for most hours. The paper concludes with recent emerging trends.
\end{abstract}

Index Terms - operating reserves, power system operation, power system reliability, power systems, reserve requirements, wind power

\section{INTRODUCTION}

$\mathrm{U}$ tility-scale wind is a relatively new resource and is increasing at such a rapid rate that utilities and system operators are becoming concerned about maintaining reliable and secure power system operation due to the increased variability and uncertainty of the generation. Wind power integration studies have been performed by numerous entities in an attempt to define, understand and quantify these impacts [1-3]. The studies typically simulate a future power system with high wind penetrations, and evaluate the impacts on the grid and the resultant incremental operating costs [3]. These studies have been maturing continuously as the state of the art advances, with each study generally building on previous ones.

Over time, grid operators have developed techniques for managing the variability and uncertainty of demand and conventional generation in a system through carrying operating reserves. Reserves are allocated (dimensioned and

H. Holttinen is with the VTT Technical Research Centre of Finland, P.O. Box 1000, 02044 VTT, Finland (e-mail: hannele.holttinen@vtt.fi)

M. Milligan and E. Ela are with the National Renewable Energy Laboratory, Boulder, Colorado, USA

N. Menemenlis is with IREQ/Hydro Quebec, Canada.

R.J. Bessa is with Instituto de Engenharia de Sistemas e Computadores do Porto (INESC TEC), University of Porto, Portugal

B. Rawn is with the Department of Electrical Sustainable Energy, Delft University of Technology, The Netherlands

D. Flynn is with the School of Electrical, Electronic and Communications Engineering, University College Dublin, Ireland

J. Dobschinski is with the Fraunhofer Institute for Wind Energy and Energy System Technology IWES, Kassel, Germany

E. Gómez-Lázaro is with Univ. Castilla la Mancha, Albacete, Spain

N. Detlefsen is with Energinet.dk, Fredericia, Denmark scheduled) for a diverse range of conditions. Reserve allocation considers reserves responding across multiple timescales - different reserves available to restore the system to a stable state after an event. Reserves are activated and utilized according to system needs during real-time operation, so it is not necessarily clear which reserve category is actually used during operation. In this paper the allocation of reserves is studied - procurement of the reserves is a subsequent step. Some reserve types can be obtained through markets or bidding procedures, while others may be a grid code required service from generators.

The term operating reserve is defined in this paper as the active power capacity that can be deployed to assist with generation and load balance and frequency control. Systems also require reactive power reserve for voltage support and a long term (planning) reserve in order to ensure system adequacy, but these aspects are not discussed in this paper.

The impact of wind on reserve requirements is a current area of interest for researchers [5]-[12] and power system operators [1], [4], [13]-[14]. System operators utilize operational principles that have evolved over time based on experience, leading in most cases to conservative deterministic rules. Rigorous methodologies and simulations are required to confirm that it is possible to reduce the deterministic reserve margins by using probabilistic methods and dynamic reserve allocation without compromising system reliability. Although the impact of large-scale solar deployment on reserve requirements has not been as deeply studied as that for wind generation, much of what follows in this article will apply to solar energy too.

The paper begins with definitions (Section II) and current practices of operating reserves (Section III). Section IV describes the impact of wind power on reserves and outlines methodologies used in estimating the increase in reserve allocation due to wind power. Section V summarizes the results from case studies. Finally, Section VI concludes with discussion on further research.

\section{OPERATING RESERVE DEFINITIONS}

Operating reserves are held for several reasons, including normal operations and anticipation of unforeseen events. Normal operation includes managing variability during the scheduling period, and any remaining forecast errors during real-time operation.

Reserves may be classified by the direction of their actions. An upward response (up-regulation) is required when there is less generation than load and can be secured from additional generating power or a reduction in participating loads. A downward response (downregulation) is required when there is more generation than 
load and can be obtained from a reduction in generating power or an increase in participating loads. Reserves can also be classified by their required response time, with different conditions requiring different response needs. For instance, reserve must be extremely fast in order to arrest a frequency decline. However, reserve that replaces other reserve categories can act more slowly, in a matter of minutes or tens of minutes. For longer timescales some systems include provision for additional reserves, balancing or supplemental or reserve, to counter forecast errors.

The system conditions that motivate the holding of reserves can themselves be classified according to whether they are rare events or not, or how fast they occur. Contingency events include abrupt changes in network configuration or network injections such as the failure of a transmission line or the loss of a generator. These events are usually dimensioned for the up-regulation need. Longer timescale events can include net-load ramps and forecast errors that occur over tens of minutes and hours. Some reserves are kept for variability and uncertainty that occurs during normal conditions. These reserves need to have both up and down-regulation components.

There are many different terms, definitions, and rules concerning what operating reserves entail. Given the variations in definition and naming convention of reserves across different systems we attempt to construct a consistent nomenclature that categorizes the different types into a common framework. Recent work has similarly categorized the different operating reserve types, for example [15]-[17]. We attempt a new categorization that may be used as high wind power penetrations become more widespread. Our main goal is for ease of understanding throughout the rest of the paper and for demonstration.

The general division used in this paper divides operating reserve into reserve allocated for non-events (normal operation dealing with deviations from schedules caused by forecast errors and variability inside a scheduling period) and reaction to rarer events, such as those caused by contingency events. These two categories have further divisions according to the required speed of response. The fast reacting reserve needs to have an automatic response (regulation and frequency responsive reserve) while the remainder can be activated manually in 10-30 minutes (load following, replacement reserve). Replacement and supplemental reserves are called upon to replenish the faster responding reserves and can also serve to mitigate the effect of forecast errors (Fig. 1 and Table I).

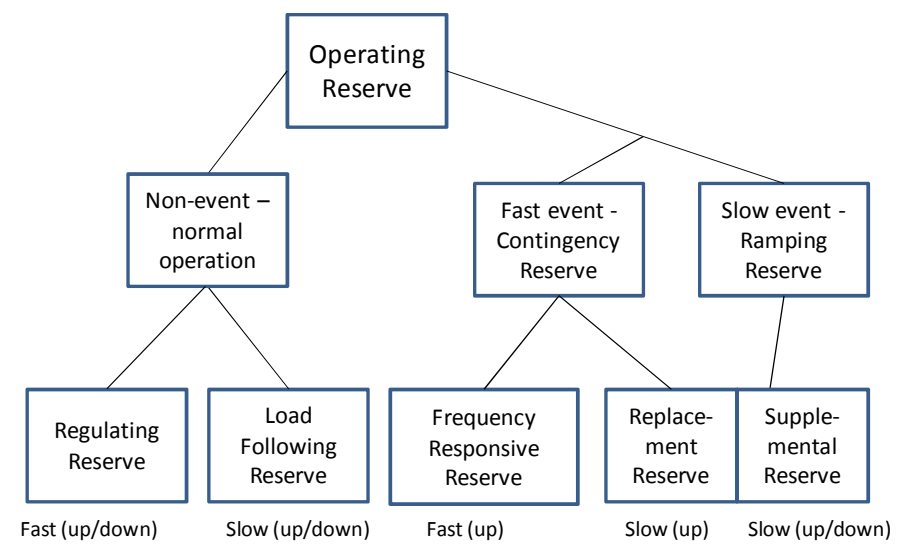

Fig. 1. General division used in this paper for operating reserve categories. Not all power systems use all these categories - some categories can be further divided into several reserve types. Ramping reserve is here taken as a new potential reserve category that is influenced by wind power.

\section{OPERATING RESERVES IN PRACTICE}

The five reserve categories proposed in the previous section are not consistent across countries.

Contingency reserve has been adopted by most systems, and is allocated for sudden loss of supply events. Balancing authorities or system operators are required to maintain sufficient contingency reserve to cover the most severe

TABLE I. RESERVE CATEGORIES

\begin{tabular}{|c|c|c|}
\hline Name & Use & Common Terms \\
\hline Operating Reserve & Any capacity available for assistance in active power balance & \\
\hline Non-event Reserve & $\begin{array}{l}\text { Capacity available for assistance in active power balance during normal } \\
\text { conditions, or those that occur continuously (no faults in system) }\end{array}$ & \\
\hline Regulating Reserve & $\begin{array}{l}\text { Capacity available during normal conditions for assistance in active power } \\
\text { balance to correct the current imbalance, is faster than economic dispatch } \\
\text { optimization, is random, and requires an automatic centralized response }\end{array}$ & $\begin{array}{lll}\begin{array}{l}\text { Regulating } \\
\text { frequency }\end{array} & \begin{array}{l}\text { reserve, } \\
\text { control, }\end{array} & \begin{array}{l}\text { regulation, load } \\
\text { primary/secondary }\end{array} \\
\text { control } & & \\
\end{array}$ \\
\hline $\begin{array}{l}\text { Load Following } \\
\text { Reserve }\end{array}$ & $\begin{array}{l}\text { Capacity available during normal conditions for assistance in active power } \\
\text { balance to correct a future anticipated imbalance and does not require an } \\
\text { automatic centralized response }\end{array}$ & $\begin{array}{l}\text { Load following, following reserve, tertiary } \\
\text { reserve, minute reserve, schedule reserve, } \\
\text { dispatch reserve, balancing reserve }\end{array}$ \\
\hline $\begin{array}{l}\text { Event Reserve (for } \\
\text { fast or slow reserve) }\end{array}$ & $\begin{array}{l}\text { Capacity available for assistance in active power balance during infrequent } \\
\text { events that are more severe than balancing needed during normal conditions }\end{array}$ & \\
\hline Contingency Reserve & $\begin{array}{l}\text { Capacity available for assistance in active power balance during infrequent } \\
\text { events like power plant outages, that are more severe than balancing needed } \\
\text { during normal conditions and is used to correct instantaneous imbalances }\end{array}$ & $\begin{array}{l}\text { Contingency reserve, disturbance reserve, } \\
\mathrm{N}-1 \text { reserve }\end{array}$ \\
\hline Ramping Reserve & $\begin{array}{l}\text { Capacity available for assistance in active power balance during infrequent } \\
\text { events that are more severe than balancing needed during normal conditions } \\
\text { and is used to correct non-instantaneous imbalances }\end{array}$ & $\begin{array}{l}\text { Ramping reserve, supplemental reserve, } \\
\text { balancing reserve }\end{array}$ \\
\hline $\begin{array}{l}\text { Frequency Responsive } \\
\text { Reserve - Contingency }\end{array}$ & $\begin{array}{l}\text { Portion of contingency reserve that is automatically responsive to } \\
\text { instantaneous active power imbalance and stabilizes system frequency } \\
\text { (primary) and returns frequency to nominal (secondary) }\end{array}$ & $\begin{array}{l}\text { Primary control reserve, frequency } \\
\text { responsive reserve, governor droop, } \\
\text { secondary control reserve, spinning } \\
\text { reserve, AGC }\end{array}$ \\
\hline Replacement Reserve & $\begin{array}{l}\text { Portion of contingency reserve that is available for assistance in replacing } \\
\text { frequency responsive reserve (primary and secondary) used during a severe } \\
\text { instantaneous event so that it is available for a subsequent instantaneous } \\
\text { event that occurs in the same direction. Can also be used and dimensioned to } \\
\text { include slower ramping events like large forecast errors. }\end{array}$ & $\begin{array}{l}\text { Tertiary control reserve, replacement } \\
\text { reserve, supplemental reserve, balancing } \\
\text { reserve, minute reserve }\end{array}$ \\
\hline
\end{tabular}


single contingency, the so-called $\mathrm{N}-1$ criteria. In large interconnected systems, rules dictate how much of each type of reserve is required in each balancing area. In particular, the automatic, frequency responsive component of the contingency reserve can be shared between regions. Reserve conventions for normal operation (non-event) disturbances have followed more varied approaches.

The North American Electric Reliability Corporation (NERC) uses the term regulating reserve to describe the fast response to normal variations in load or generation, both upward and downward [18]. Regulating reserve requirements are usually not explicitly defined, but balancing areas need to meet their Control Performance Standards (CPS1 and CPS2). In some areas that have high penetrations of wind power, such as the Electric Reliability Council of Texas (ERCOT), the forecast wind power output is considered when determining the operating reserve requirements [19]. Hydro Quebec requires three categories of reserves not dimensioned by contingencies: frequency regulation reserve (AGC), load following reserve and energy balancing reserve to offset forecast errors (following and ramping reserve). In Europe, the European Network of Transmission System Operators for Electricity (ENTSO-E) defines reserve in three categories: primary, secondary and tertiary control. The amount of reserve available in the individual control areas is basically determined by their respective size [20]. Primary control reserve requirements are based on the largest credible event for the interconnection and are distributed by each transmission system operator (TSO) based on their energy production. Secondary control reserve is dimensioned to account for both generation outages and normal variations with a statistical based formula for TSO regions to follow. However, the way in which reserves are used in individual control areas differs. In some countries tertiary reserve is used to free the secondary reserve in order to be ready for the next disturbance. In other countries (like Denmark) schedules are continuously updated and tertiary reserve is activated in order to minimize the expected imbalance, so as to minimize the need and use of automatic reserves. In Spain, an additional active power reserve, called deviation reserve, helps to balance large differences (> $300 \mathrm{MWh}$ ) between scheduled generation and the forecasted demand.

Currently, ramping reserve is not a requirement in any power system. However, there are discussions to include this additional reserve category in the US [21]. Also, in some systems a supplemental reserve category is included for slower events, such as deviation reserve in Spain [4] and balancing reserve in Hydro Quebec [22]-[24].

\section{METHODS TO ASSESS WIND POWER IMPACTS ON RESERVE ALLOCATION}

When studying the impact of wind power on each reserve category separately, a common conclusion is that wind power does not impact the contingency reserve requirement [4], [13], [25], [26]. This is because wind power plants that could trip off instantaneously are smaller (MW) than the largest single contingency (usually of the order of 500 to $2000 \mathrm{MW}$ ) - assuming a fault-ride-through capability is available from large scale wind power. Furthermore, wind plant output does not change fast enough to constitute a contingency event; large ramps, even those caused by overspeed cut-out, evolve over time [26]. Instead, wind power will mostly impact the non-event (regulation and load following) category of reserve. The impact on the second-tosecond response (regulation) is also seen to be significantly lower than the impact on the load following time scale (10$30 \mathrm{~min}$ ) [4],[14],[22]. Currently, measured wind power ramping rates (for example extreme values of $1500 \mathrm{MW} / \mathrm{h}$ in Spain) are much lower than demand ramping rates (up to $4000 \mathrm{MW} / \mathrm{h}$ in Spain) [4]. At high wind penetration levels, wind power will also introduce events of larger variability and large forecast errors that could be categorized as a slow event (creating a need for supplemental / replacement reserve and ramping reserve). In addition, there are several new methods that calculate the total reserve requirement for the system taking both contingencies and load / wind uncertainty into account.

Traditionally, the term 'reliability' refers to ensuring resource adequacy to accommodate rare events in long-term planning, and also the ability to maintain the system operationally. In the context considered here, reliability concepts are applied to the operational planning horizon which spans a time frame from a few minutes to a few days ahead, and thus is referred to as short-term, or operational reliability. A common approach compares the uncertainty and variability before and after the addition of wind generation. Introducing wind generation requires the allocation of additional reserves to maintain a desired reliability level. The computation of short-term reliability requires knowledge of the uncertainty or variability of the demand, wind generation and other generation. For wind power, the forecast horizon time scale is also a crucial assumption as the uncertainty will reduce more significantly than for demand at shorter time scales.

In what follows the analysis is separated into deterministic and probabilistic methods. An advantage of deterministic methods is their simplicity - but they may lead to overestimating the reserve requirement and costs for the system. Probabilistic methods are more complex and often computationally intensive, but they allow the definition of an imposed reliability criterion and provide the corresponding reserve level. Both approaches may be either static or dynamic, whereby static methods assume the same reserve level regardless of system conditions, while dynamic reserve modifies the target level, often as a function of load and wind power. The various system disturbances and events can usually be considered independent when estimating the reserve requirement, so we only discuss here methods for statistically independent events or variations.

\section{A. Deterministic methods}

Deterministic methods are designed to protect the system against severe disturbances. They don't consider less severe events, their probability of occurrence or any dependence between events. Deterministic methods linearly sum the reserve requirements from different possible events. As there are no correlations between the uncertainties of generation outages, load and wind, calculating reserve requirements in this way will overestimate the need, which is costly. One way to overcome this problem is to apply some form of geometric addition instead of simple 
arithmetic addition (Fig. 2). Another approach is to include reserve for only part of the maximum possible event when summing up with other extreme events. The Spanish TSO, for example, accounts for the low probability of simultaneous events by taking $2 \%$ of the forecast value for load and the difference between the expected wind power level and a lower wind level with an $85 \%$ probability of being exceeded. These variations represent the maximum possible instantaneous events for load and wind combined with the maximum loss of generation [4].
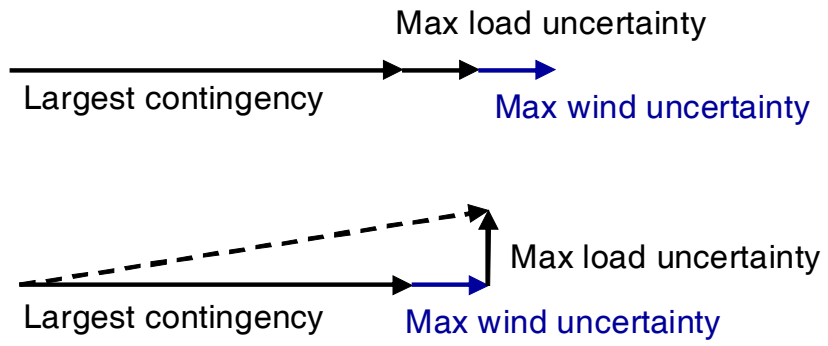

Fig. 2. Deterministic reserve allocation examples

\section{B. Statistical methods-Gaussian non-correlated inputs}

Assuming that load and generation errors can be represented by normal uncorrelated distributions, then the variance of the net error including wind is given by:

$$
\sigma^{2}\left(\tilde{\varepsilon}_{\text {net_error }}\right)=\sigma^{2}\left(\tilde{\varepsilon}_{l}\right)+\sigma^{2}\left(\tilde{\varepsilon}_{w}\right)
$$

where $\varepsilon_{l}$ is the load variability or forecast error depending on the type of reserve, and $\varepsilon_{g}$ is the generation variability or forecast error from wind power generation. The additional reserves, $\Delta \operatorname{Res}_{w}$, required to cover the increase in variance of the net error (or a regulation signal obtained from the net error) due to the integration of wind energy with a certain confidence level is computed as:

$$
\Delta \operatorname{Res}_{w}=n\left(\sigma\left(\tilde{\varepsilon}_{\text {net_error }}\right)-\sigma\left(\tilde{\varepsilon}_{l}\right)\right)
$$

This is referred to as the n-sigma method and is illustrated in Fig. 3 using 1 year of day-ahead forecast information for wind sites in the Netherlands and load (33\% wind energy penetration against net load) [28]. Typically $n$ is selected to cover almost all occurrences of wind variability with a certain confidence [29].

For $n=3$, the reserves would cover $99 \%$ of the variations. However, wind variability and wind forecast errors are not normally distributed, at least not from experience so far from limited areas like Germany [30]. Instead, there will be extreme events in the tails of the distributions not covered by a Gaussian approximation. To cover these un-modeled events, sometimes higher values of $n$ are suggested: between 4 and 6 for regulation and between 2 and 2.5 for loadfollowing [29]. To take account of non-normally distributed wind variability or forecast errors, an exceedence level on the net error distribution can be used. The differences between consecutive data points are sorted by magnitude, with the absolute maximum and various percentile values taken as measures of non-event fluctuations.

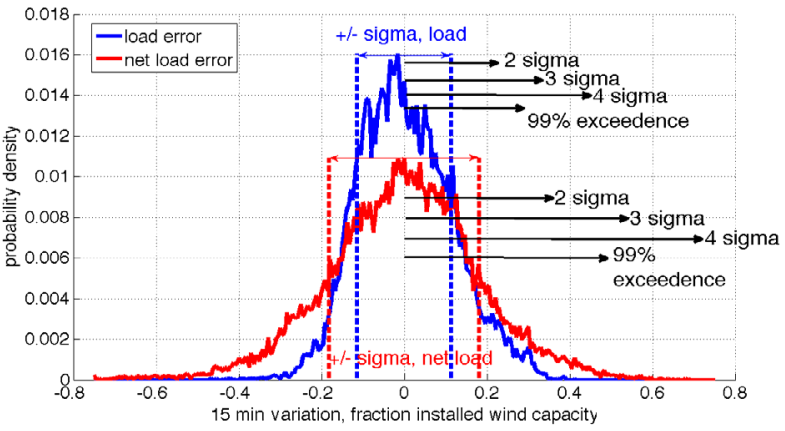

Fig. 3. Distribution of load variability and net load variability for different confidence levels. The difference between the $99 \%$ exceedence level, or 3 (or other multiples of) sigma can be applied as an increase in the reserve requirement due to wind power.

\section{Convolution methods - non-Gaussian non-correlated inputs}

Based on available data for wind and load variability and their associated uncertainties, distributions of the variations or uncertainties can be calculated. Superposition of the probability density distributions (PDD) for different uncertainties can be achieved by recursive convolution of the PDDs, based on the assumption that power plant outages, load and wind power forecast errors are statistically independent (see Fig. 4). Referred to as the convolution method of computing the reserves, the resultant PDD includes the magnitude and frequency of all potential imbalances (power deficits and surpluses) that require an upward or downward reserve response.

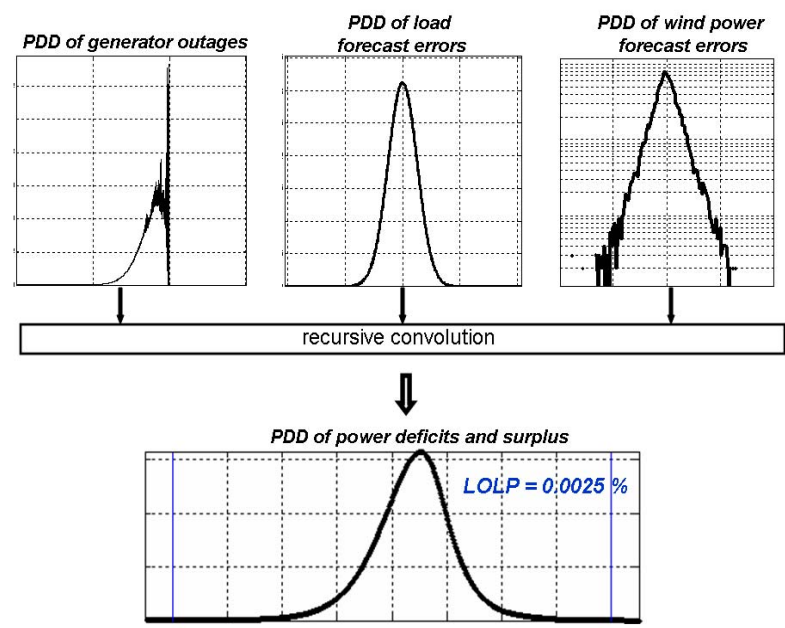

Fig. 4. Calculation of reserve requirements based on power station outages, and load and wind power forecast errors

To estimate the impact of wind power a certain measure of reliability can be applied to determine the reserve needs before and after wind is included. In Fig. 4, a 'loss of load probability' (LOLP) is used as the reliability level, defining the probability that the allocated reserve is insufficient to balance the demand and generation at each time step (vertical blue lines in Fig. 4) [30]. A fast Fourier transform can also be applied to convolve the wind power, load and conventional generation uncertainties. The convolution computes the system generation margin distribution (i.e. difference between load and generation), and from this distribution risk/reserve and risk/reserve cost curves are derived [12]. Mathematically the risk is given by [23], [24]: 


$$
\begin{aligned}
R_{0}(t) & =\operatorname{Pr}\left[\varepsilon_{l}(t)+\varepsilon_{u}(t)-\varepsilon_{w}(t) \geq \text { Res }\right] \\
& =1-\operatorname{Pr}\left[\varepsilon_{l}(t)+\varepsilon_{u}(t)-\varepsilon_{w}(t) \leq \text { Res }\right]
\end{aligned}
$$

where $\varepsilon_{l}(t)+\varepsilon_{u}(t)-\varepsilon_{w}(t)$ represents the net error and $R_{0}(t)$ is the risk corresponding to a given level of reserve. The subscripts $l, u$ and $w$ represent demand, conventional generator unavailability and wind generation respectively. With increasing levels of wind generation, the necessary reserve to maintain the same level of risk increases, represented by the quantity $\Delta$ Res. Alternatively, if the reserve level is unchanged, then additional risk is incurred by the system represented by the quantity, $\Delta R$. The reserves required to meet a certain reliability level can be determined directly from the global net error distribution. Fig. 5 illustrates a risk / reserve curve for an instance of time.

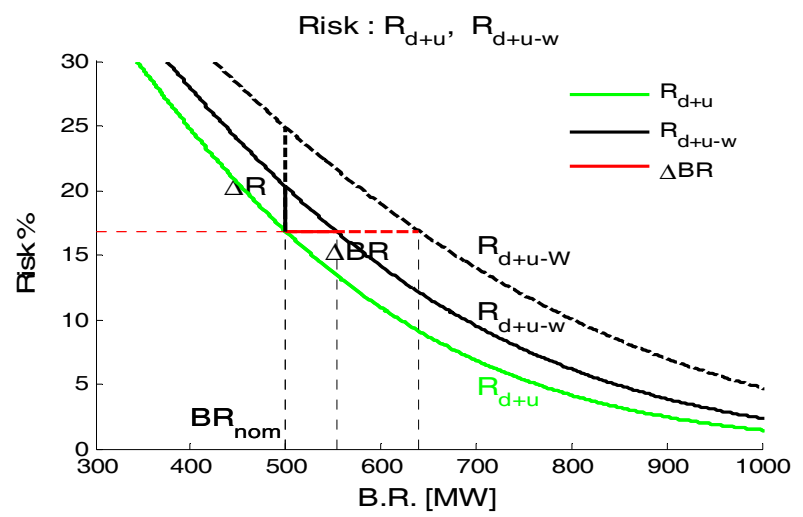

Fig. 5. Risk that generation plus reserves (B.R.) is insufficient to match the load at a given time, with and without wind power

\section{Data Requirements}

The data required to perform these calculations can be challenging to obtain. Often the uncertainties are estimated by distributions, for example the system demand deviation is fitted to a Gaussian distribution, thermal unit outages are modeled through a Poisson distribution, and wind forecast errors follow a probability density function derived from a Weibull distribution [4], or approximated as a function of the generation levels, using a Gamma-like distribution [24]. In ERCOT the Cauchy distribution accurately describes the forecast errors [32]. Monte Carlo simulations of demand and wind forecast errors and unexpected outages of thermal units can also be used to assess the theoretical uncertainty [4]. Conventional generation uncertainty can be represented by a capacity outage table computed using the unit's outage replacement rate. The distribution of power station outages should be adapted to the power plant mix and the individual probabilities of failure occurrence that lie within the same time frame as other uncertainties (replacement reserve for outages and load following reserve for other uncertainties).

Once sufficient data (past forecasts and measurements) have been collected, their statistical characteristics can be generated for different situations, e.g. by time of day and time of year, or for specific meteorological conditions. To study the impact of wind power on reserve needs over several timescales, very short period variability needs to be separated from 10-60 minute variability. Catching large error events for wind power would require several years of data to obtain results with adequate statistical reliability. For example, the LOLP value for estimating the reserves in Fig. 4 is very small at $0.0025 \%(\sim 13 \mathrm{~min} / \mathrm{a})$ so that the empirical data set of historical wind power forecast errors with a temporal resolution of 1 hour might exceed a time period of several decades before results are obtained that are statistically significant. For short-term forecasts with horizons of 2-3 hours the dependency on the used data set is not as critical. For the operational domain (short-term reliability assessment), wind power and load uncertainties can also be provided using a probabilistic forecasting system. This can reduce the problem of catching large error events not present in simulated distributions, and provide a dynamic characterization of the uncertainties. However, several years of data would be required to train a statistical model which can capture extreme storm event.

As forecast accuracy is steadily improving, the assessment of future impacts due to wind often means simulating the uncertainty due to wind power forecast errors. These errors depend on the quality of the prediction system and the analyzed forecast horizon, which also illustrates the importance of reducing large forecast errors by optimizing wind power forecast tools.

\section{E. Dynamic allocation}

Since variability and forecast uncertainties vary over time, using constant reserve levels will either lead to varying risk levels, or maintaining a constant reliability or risk level will require varying reserves. Developing dynamic reserve computation tools will help especially with higher wind penetration levels to avoid the need to carry large amounts of reserves at every instant [12],[26], [33]. All the above methods can also compute reserves dynamically.

\section{RESULTS FROM CASE STUDIES}

Results from case studies are grouped according to different methodologies used - static and dynamic. The reserve categories from Section II are used, and the terminology used in the power system has been indicated with italics.

\section{A. Increase in reserve requirements - static calculations}

\section{1) Netherlands - comparing methods}

The peak load of the Dutch power system is $21 \mathrm{GW}$ and scenarios have been studied for installed wind capacities ranging from 2-12 GW, which amounts to the provision of $5-33 \%$ of annual energy [33]. To provide a comparison of different methods, multi-site wind power data [28] were combined with load data and associated day-ahead forecasts. In Fig. 6, the risk of exceeding a certain imbalance level is shown for several error distributions (load alone, wind alone and net load) as well as their convolution and the subsequent convolution with generation outages. Vertical lines show the total reserve requirement for the system based on deterministic methods (simple sum, A1, and geometric sum, A2) and probabilistic methods (3 standard deviations (B1), 99\% exceedence (B2), and $0.25 \%$ LOLP from convolution (C)). The sum of the largest ramp rates and outages clearly overestimates the reserve requirement - the geometric sum also yields a larger requirement than the maximum point of the distribution. 


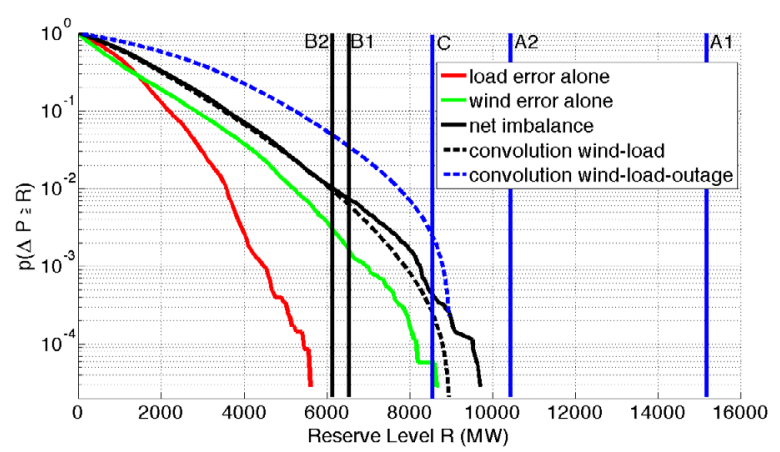

Fig. 6. System reserve requirements (33\% wind penetration in Netherlands) calculated from net wind and load forecast errors and from also including generation outages (blue). The deterministic reserve calculations summing the maximum variations (A1, simple, A2, geometric) are also shown.

\section{2) Germany - impact of forecast horizon}

An increase in reserve requirements for load following and replacement reserve (minute reserve) was estimated with a convolution approach, for two scenarios in Germany: wind power from the year 2009 ( $25 \mathrm{GW}, 7.5 \%$ of gross demand) and a future 2020 scenario [35] with an installed wind power capacity of $50 \mathrm{GW}$ (19.5\% of gross demand). Power plant outages were based on the German power plant mix of 2009 [36], while an unbiased normal distribution was assumed for the load forecast errors with a standard deviation of about $1.7 \%$ of the respective peak load [37].

The PDD of the wind power forecast errors were obtained from historical day-ahead forecasts and short-term forecasts with horizons of 1-4 hours based on the time period July 2008 to December 2009 while also including and excluding data from January 2007. A considerable improvement in forecasting accuracy was assumed for the year 2020, based on a constant improvement of the mean absolute error (MAE): $30 \%$ improvement of the day-ahead forecast and $40 \%$ improvement of the (1-4 h) short-term forecasts.

Forecasts with a 2-3 hour horizon lead to an enormous reduction of the wind induced uncertainty, especially for the larger errors - this is a lead time that seems to be sufficient for final purchases and sales in the intra-day market. Consequently, only smaller forecast errors must be balanced in the frame of load following or replacement reserve. The comparisons in Fig. 7 also reveal that the improved forecasts assumed for 2020 are crucial and can lead to reduced wind induced reserve requirements in the future even with higher wind penetrations. The error bars in Fig. 7 have been calculated for both time periods of wind data (July 2008 to December 2009, including and excluding data from January 2007). Corresponding analysis in [30] has shown that integrating the forecast errors observed in January 2007 when the storm event 'Kyrill' occurred lead to a significant increase in the estimated minute reserve, up to about $60 \%$ (see Fig. 8) when estimating with day-ahead forecast errors, but do not impact the 2-3 hours forecast error calculation as much. In general, storm events that cause large-scale wind turbine cut-outs and damage to the transmission system result in very large forecast errors, especially for longer lead times ( $>6$ hours). Shorter horizons benefit significantly from wind persistence information.

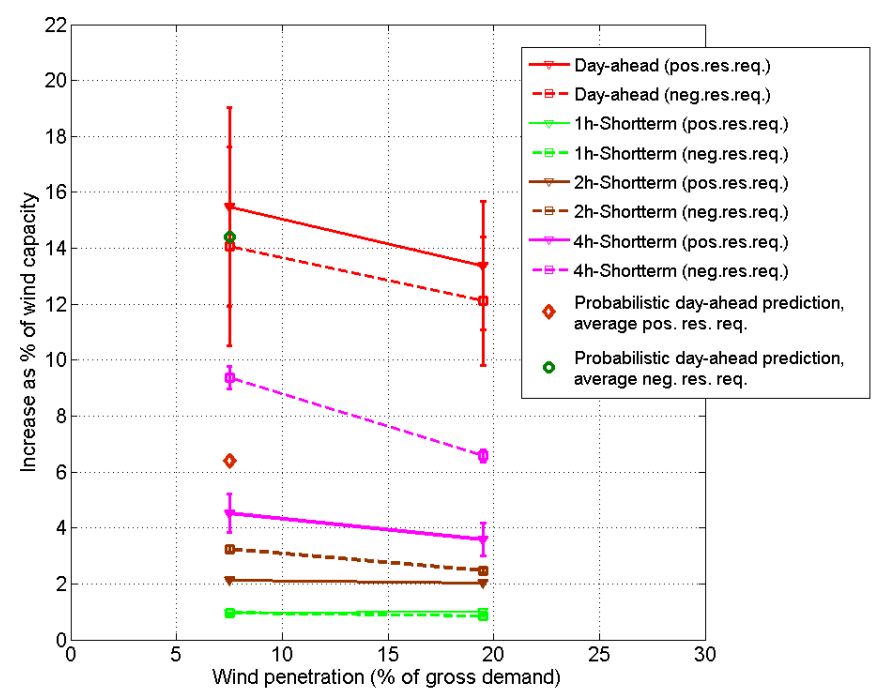

Fig. 7. Wind power induced (minute) reserve requirements for two wind penetration levels in Germany (7.5 and 19.5\%) calculated for different forecast horizon uncertainty $(1,2,4$ hours and day-ahead) and assuming a considerable improvement in forecast accuracy for $19.5 \%$ penetration level
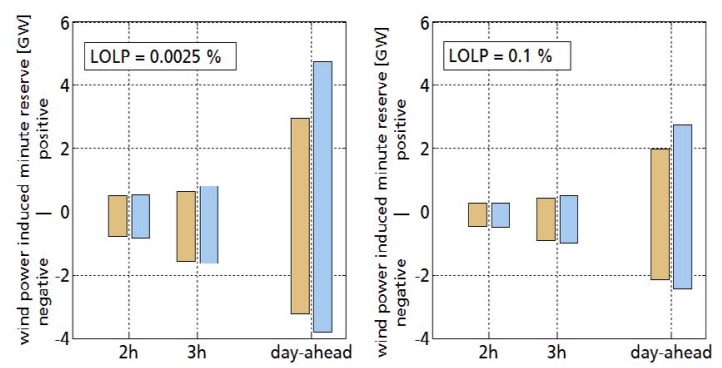

Fig. 8. Wind power induced (minute) reserve requirements for Germany ( $7.5 \%$ penetration), for two reliability levels (loss-of-load-probabilities of $0.0025 \%$ for left plot and $0.1 \%$ for right plot). The reserve estimation is based on real wind power forecast data with three lead times ( 2 hours, 3 hours, day-ahead), from July 2008 to Dec 2009 (orange bars), and including the severe storm event of Jan 2007 (blue bars).

\section{B. Dynamic calculations for reserve requirements}

\section{1) US studies}

The Eastern Wind Integration and Transmission Study (EWITS) estimated reserve requirements for 20-30\% wind penetration levels [26]. Recognition of the boundary between operating reserves and what is extracted from subhourly energy markets impacted on the calculation methods selected. Regulation reserve was estimated with the 3 sigma method, but since the wind variability component was considered small, the method combined the wind power forecast error (10-min-ahead persistence) with the reserve level (1\% of load). The reserve was determined as an hourly dynamic requirement of the standard deviation of the tenminute errors, which was a function of wind production $\left(\sigma_{\mathrm{st}}(\right.$ HourlyWind $\left.)\right)$. The calculation in (4) is based on a regression analysis of the wind (or solar) data [38].

$$
\text { Reg Req }=3 * \sqrt{\left(\frac{1 \% \text { Hourly Load }}{3}\right)^{2}+\sigma_{S T} \text { (HourlyWh }}
$$

The load following reserve was estimated from the hour- 
ahead wind forecast error: one standard deviation of the hour-ahead forecast error was required to be spinning, and two standard deviations could be non-spinning. Dynamic reserve allocation was used for both regulation and load following - which were combined as an hourly time-series to determine the additional on-line reserve in the production simulation analysis.

The above approach has been applied in the evaluation of the proposed Energy Imbalance market in the Western Interconnection of the United States [38]. Considering a single balancing area (BA), Fig. 9 shows how each of the three reserve types varies as a function of the wind output, expected variability, and forecast error for a sample week. The level of reserve is also driven by the relatively small size of the BA. Fig. 10 shows the annual data corresponding to the sample week, organized as a duration curve. The wind generation is $2900 \mathrm{MW}$ ( $20.3 \%$ energy penetration).

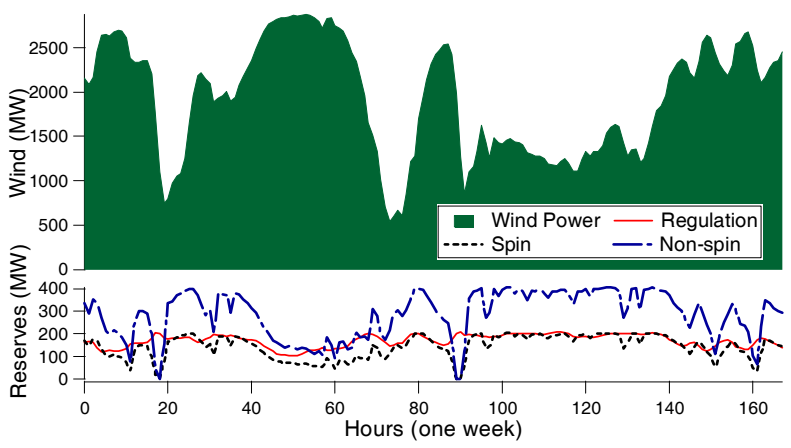

Fig. 9. Varying standard deviation based on wind output leads to a dynamic reserve requirement.

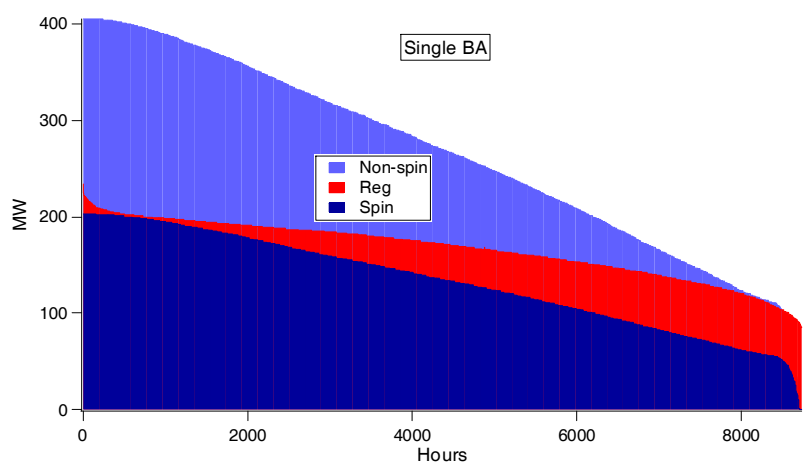

Fig. 10. One year duration curve of dynamic reserve calculation, showing all three types of reserves calculated

Table II shows the impact of footprint size on the relative reserve levels for each category type. The upper part of the table represents the maximum hourly wind generation (\%), whereas the lower portion is summarized in terms of energy. It is clear that larger electrical footprints can mitigate the relative reserve requirement for all categories.

\section{2) Quebec}

The peak Hydro Québec (HQ) generation capacity is approximately $40 \mathrm{GW}$, and an anticipated wind power penetration level of $10 \%$ by 2016 is studied (currently 4000 MW wind, and approximately $4 \%$ by energy penetration). In HQ two distinct studies were conducted to evaluate the influence of wind power on reserve requirements. The first of these was performed using a simulator in order to obtain the most accurate analysis of the impacts of wind generation on the efficient use of generators providing AGC and load following services [22]. In HQ the impact of wind power on slower reacting balancing reserve (supplemental reserve) is currently being evaluated using a dynamic reserve calculation [23], [24]. This reserve ensures the short-term reliability of the power system over a time horizon of 1 to 48 hours ahead. Reserves are computed using a convolution method, in order to meet a specific risk level or LOLP target, for time horizons of 1 to 48 hours ahead (Fig. 5). Distributions of all the forecast errors were developed from past forecast error data. The anticipated risk was then computed for each forecast lead time as a function of the net forecast error distribution for a predetermined level of balancing reserve (Fig. 11 shows an example of the calculation for one time instant, with the difference in reserve $\triangle \mathrm{BR}$ due to wind power).

Risk levels for 1-48 hour ahead reserve can be higher (up to $5 \%$ over the day-ahead horizon) compared with reserve categories acting intra-hourly, since uncommitted resources can also be called upon to remedy undesirable events. The choice of risk level is primarily an economic consideration. The conclusion to be drawn from results obtained so far is that with current HQ balancing reserves being high and risk levels low, little additional balancing reserves are required to integrate $3000 \mathrm{MW}$ of wind power capacity.

TABLE II: ENERGY IMBALANCE MARKET IN WESTERN INTERCONNECTION

\begin{tabular}{|l|c|c|c|}
\hline & \multicolumn{2}{|c|}{$\begin{array}{r}\text { Maximum reserve to maximum non-coincident } \\
\text { hourly wind generation }(\%)\end{array}$} \\
\hline $\begin{array}{l}\text { Western } \\
\text { Interconnection }\end{array}$ & 4.04 & 3.13 & 6.27 \\
\hline Single BA & 8.16 & 7.06 & 14.12 \\
\hline & $\begin{array}{c}\text { Wind Energy } \\
(\mathrm{GWh})\end{array}$ & $\begin{array}{c}\text { Demand } \\
(\mathrm{GWh})\end{array}$ & $\begin{array}{c}\text { Wind } \\
\text { Penetration }(\%)\end{array}$ \\
\hline $\begin{array}{l}\text { Western } \\
\text { Interconnection }\end{array}$ & 143,382 & 634,276 & 23 \\
\hline Single BA & 9,953 & 48,935 & 20 \\
\hline
\end{tabular}

\section{3) Ireland and Northern Ireland}

The All Island Grid Study examined the ability of the combined Ireland and Northern Ireland system to integrate up to $8 \mathrm{GW}$ wind power for a projected peak load of 9,618 MW [39].

The demand for reserves over the time frame $90 \mathrm{~s}-5$ min (tertiary reserve, band 1 - frequency responsive reserve category) is illustrated in Fig. 12 on a weekly averaged basis. The reserve is dynamically allocated, assuming an outage of the largest online in-feed occurring concurrently with a fast decrease in wind power production. The size of the largest unit is $480 \mathrm{MW}$, while the wind-induced reserve requirement will be a function of the current wind levels and the installed wind capacity. For portfolio 6, with an installed wind capacity of $8000 \mathrm{MW}$, this additional reserve requirement peaks at $225 \mathrm{MW}$. Hence, while variable generation requires extra reserve, the largest factor remains the loss of the largest conventional unit. So, for example, during weeks 31 to 34 when a scheduled outage of the largest unit on the system occurs the demand for contingency reserve reduces significantly. 


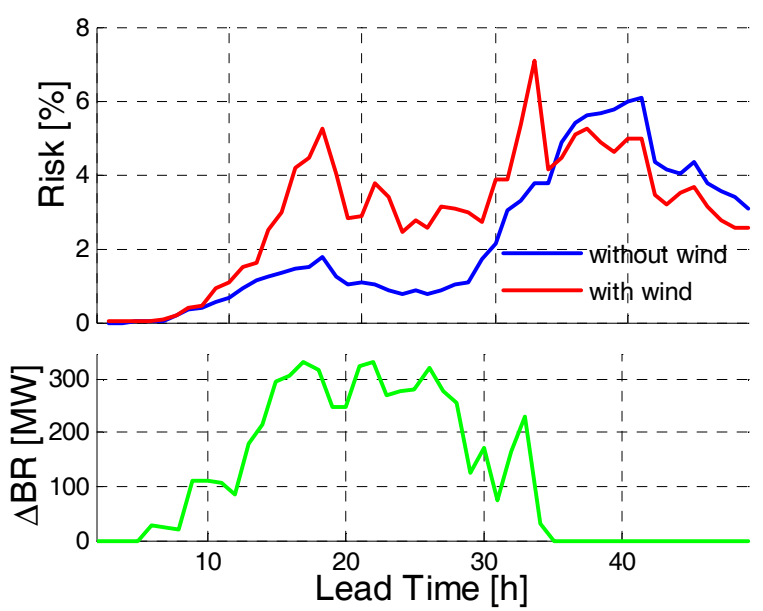

Fig. 11. Risk and additional balancing reserve required to maintain the same risk level with / without $3 \mathrm{GW}$ wind power in the $37 \mathrm{GW}$ HQ system

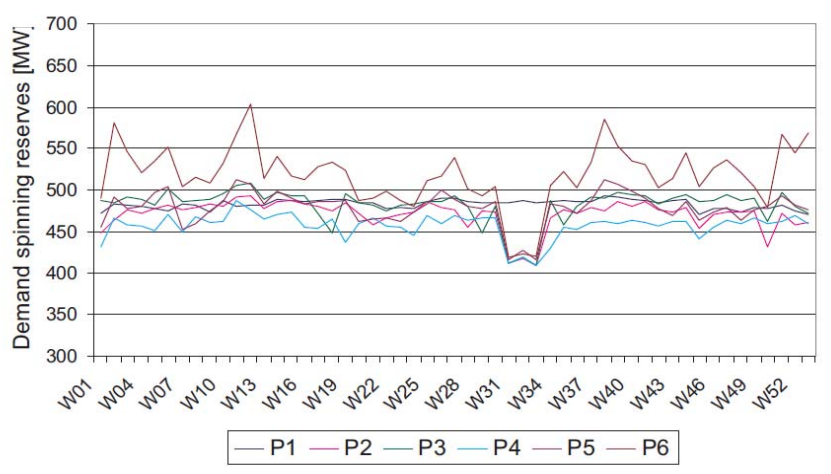

Fig. 12. Weekly demand for spinning reserve for each generation portfolio

The WILMAR model used in the study implements rolling unit commitment and has stochastic optimization functionality. Replacement reserve requirements (combining the categories of replacement and load following reserve) were simulated dynamically as a function of the installed wind power and the net load forecast error (including the possibility of forced outages) over longer timelines, with a highly simplified representation of reserve provision in the Ireland and N. Ireland system, Fig. 13 . The $90^{\text {th }}$ percentile of the deviation between the compared power balances must be covered, based on current practice [40].

\section{Comparing deterministic and probabilistic approaches \\ 1) Portugal}

Portugal has a peak load of $9.4 \mathrm{GW}$, and at the end of 2010 the installed wind power capacity was $3.85 \mathrm{GW}$, generating $17 \%$ of gross demand. A demonstration for the Portuguese system operator (REN) compared two dynamic methods of calculating the reserve compared with the reserve that was actually activated in real-time operation during October 2010 to May 2011 [41].

The robust reserve setting (RRS) tool defines the requirements for two reserve categories: one reserve share to react to events (contingency reserve), and a second share for non-events (load following reserve) - called "tertiary reserve" (activated manually in $15 \mathrm{~min}$ ). The tool is based on convolution technique that uses a Fast Fourier Transform to convolve the wind power, load and conventional generation probabilistic forecasts [12]. The convolution computes the system generation margin distribution (i.e. difference between load and generation), and from this distribution risk / reserve and risk / reserve cost curves are derived. These curves form inputs to the decision-aid phase, where, based on decision maker preferences and attitude towards risk, the reserve requirements for the next day and upcoming hours are defined.

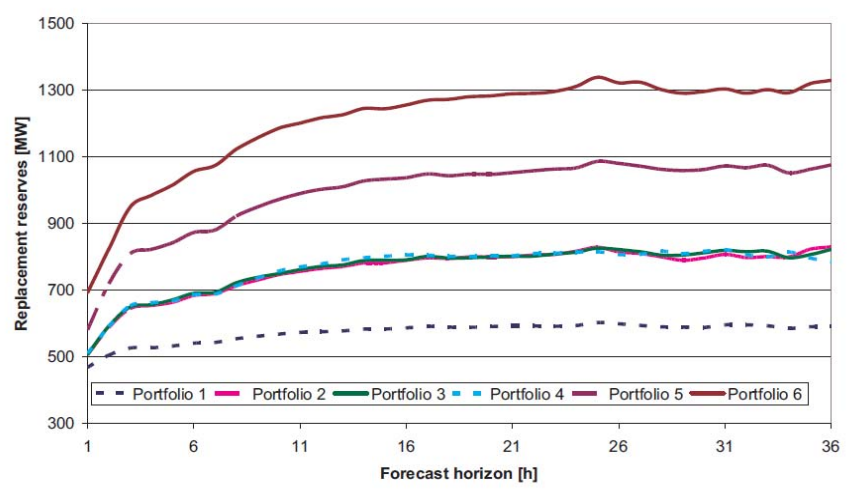

Fig. 13. Average demand for replacement reserve dependent on forecast horizon for each generation portfolio.

A deterministic rule of $2 \%$ of the forecasted load, $20 \%$ of the forecasted wind power and the largest unit in the system (435 MW) gave another dynamic reserve calculation.

Results from Table III show how often the proposed RRS tool reserve suggestions were insufficient as compared to the actual use of reserves during that period. This percentage should match the reference risk level (i.e. a loss of load probability threshold equal to $0.1 \%$ and $0.5 \%$ ). Since the two reference risk levels lie inside the confidence interval, the RRS is well calibrated for these two risk levels.

The results for the deterministic rule give an idea of the embedded risk level. The deterministic rule leads to a higher risk than RRS, since the latter provides information about the level of risk associated with the reserve level setting, and avoids high risk situations, which increases consistency and robustness when setting the reserve levels. Fig. 14 depicts the distribution of reserve levels indicated by RRS (for $\left.\operatorname{LOLP}_{\text {ref }}=0.5 \%\right)$ and the deterministic rule. The reserve values suggested by the deterministic rule are more concentrated in the histogram, ranging between 500 and $1400 \mathrm{MW}$, while the RRS suggestions are more varied covering a wide range of reserve values.

TABLE III

COMPARISON BETWEEN RRS AND DETERMINISTIC RULE FOR THE TWO RISK LEVELS. [C.I. IS THE 95\% CONFIDENCE INTERVAL]

\begin{tabular}{ccc}
\hline \hline & LOLP $_{\text {ref }}=0.1 \%$ & LOLP $_{\text {ref }}=0.5 \%$ \\
\hline \multirow{2}{*}{ RRS Tool } & $0.23 \%$ & $0.40 \%$ \\
& C.I. $.95 \%[0.09,0.34] \%$ & C.I..$_{95 \%}[0.23,0.57] \%$ \\
Deterministic Rule & \multicolumn{2}{c}{$0.78 \%$} \\
\hline \hline
\end{tabular}

\section{2) Spain}

Spain has a peak load of $45.4 \mathrm{GW}$, and at the end of 2010 the installed wind power capacity was $20 \mathrm{GW}$, generating $16 \%$ of gross demand. The main influence of wind power in the Spanish power system is on non-event load following and slow event supplemental reserves that have the capacity to change generation level quicker than the starting time of 
the thermal units [4]. Similar to the Portuguese case, the Spanish TSO has compared deterministic and probabilistic methods for reserve allocation in the current power system, for the first 120 days of 2010 [4].

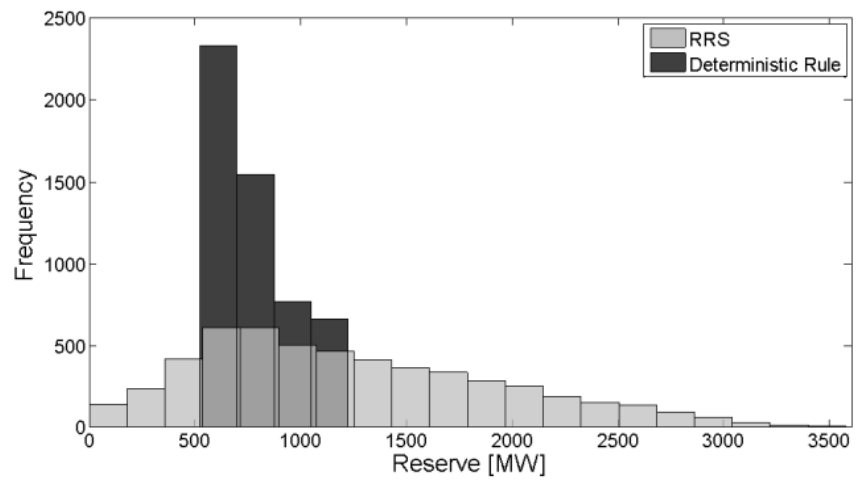

Fig. 14. Reserve distribution suggested by RRS and deterministic rule for upward reserve

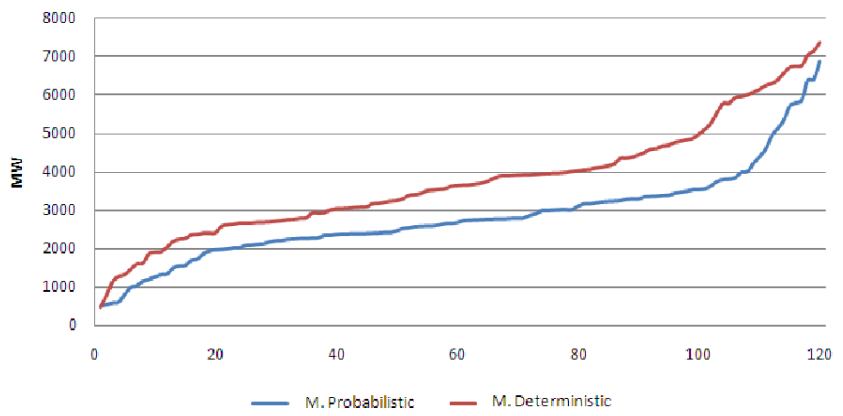

Fig. 15. Reserve calculated and actually deployed during hourly peak load period over 120 days of operation (Source: Red Electrica)

The probability density distributions of the forecast errors for load and wind generation have been calculated using real data, assuming errors are distributed as a Gaussian distribution for load and a Weibull distribution for the wind. In the case of generation outages, the probability of generation failure is given by a Poisson distribution. A Monte Carlo simulation is then run to calculate the PDD, with the $99 \%$ percentile value defining the reserve requirement. The results of Fig. 15 show that the reserve requirements calculated using the probabilistic Monte Carlo method are smaller and closer to the real requirements than the current deterministic method.

\section{CONCLUSION AND DISCUSSION}

In this article a general framework is provided for categorizing reserves than can be used when comparing the many diverse approaches for calculating wind-induced reserves. Different time scale categories are identified for non-event and event reserves. With new methods that calculate the total reserve requirement for the system taking both contingencies and load/wind uncertainty into account all the reserve categories defined are not that important in comparison. The important distinction that remains is the division on time scales of reserve activation.

Several methods are emerging for calculating the reserve impact of wind energy. The common evolution observed is the adoption of approaches that are dynamic: specific system states are taken into account so that over-scheduling of reserve is minimized. Dynamic approaches can be either deterministic or probabilistic, although deterministic approaches may be based in part on statistical variations of the wind and load, and therefore possess a probabilistic component. Other approaches make use of more advanced probabilistic methods, such as calculating dynamic LOLP values to derive a reserve level that holds the risk constant. One advantage of the probabilistic approach is that it gives information about the level of risk to the system operator. This will be more important in power systems with high wind power penetration. The tools for reserve allocation are also likely to be extended to the operational domain, as system operators must know what risk they are taking on a daily basis.

There is no difference in the methodologies used so far concerning whether wind farms are more dispersed or more concentrated - this will be reflected in the data. The data requirements are more challenging for the dispersed case. As more wind power is installed, it will be easier to access representative data on the variability of dispersed wind power. However, the forecast errors are still difficult to estimate for future wind power scenarios. In regions where wind power forecasting is not yet implemented, some basic assumptions about the forecast error level must be assumed initially, and perhaps more simple deterministic methods used. However, estimates of the reserve requirements should be updated once some wind power becomes operational and more accurate data is available.

The use of dynamic techniques, along with the presented reserves framework, show that the required reserve depends on both the time scale and the speed of the required response. One key implication is that ancillary service markets may evolve to provide a menu of reserve products that can be tailored to meet the need of systems with large amounts of wind power.

A comparison of the results for different methods is challenging. There is no simple way of presenting the results of a dynamic, varying reserve requirement. One approach would be to present it as a duration curve or a range over an average reserve level, but for this at least one year of data should be available. One result that has been seen from several case studies so far is that even if more reserve response will need to be scheduled this does not mean that new capacity needs to be built. There will be challenging situations when all power plants are at their minimum or shut down, at times of high wind and low load. In these cases providing reserve from wind power is one option. Wind power will also mean different amounts of up and down reserve will be needed.

\section{ACKNOWLEDGMENT}

This paper is a result of the international collaboration IEA Wind Task 25 Design and Operation of Power Systems with Large Amounts of Wind Power.

\section{REFERENCES}

[1] H. Holttinen, P. Meibom, A. Orths, F. van Hulle, B. Lange, M. O'Malley, J. Pierik, B. Ummels, J.O. Tande, A. Estanqueiro, M. Matos, E. Gomez, L. Söder, G. Strbac, A. Shakoor, J. Ricardo, J.C. 
Smith, M. Milligan \& E. Ela, Design and operation of power systems with large amounts of wind power, VTT Research Notes 2493, Espoo, Finland, 2009.

[2] J.C. Smith, M. Milligan, E. Demeo, and B. Parsons, "Utility Wind Integration and Operating Impact State of the Art," IEEE Trans. Power Syst., vol. 22, pp. 900-908, Aug. 2007

[3] M. Milligan, E. Ela, D. Lew, D. Corbus, and Y. Wan. Advancing Wind Integration Study Methodologies: Implications of Higher Levels of Wind. WindPower 2010 Dallas, Texas May 23-26, 2010, available at http://www.nrel.gov/wind/systemsintegration/

[4] A. Gil, M. de la Torre, R. Rivas, "Influence of Wind Energy Forecast in Deterministic and Probabilistic Sizing of Reserves," 9th International Workshop on Large-Scale Integration of Wind Power into Power Systems as well as on Transmission Networks for Offshore Wind Power Plants, October 2010, Quebec.

[5] G. Dany, "Power reserve in interconnected systems with high wind power production," Proceedings of IEEE Porto Power Tech Conference, Porto, Portugal, September 2001.

[6] R. Doherty and M. O'Malley, "A new approach to quantify reserve demand in systems with significant installed wind capacity," IEEE Trans. Power Syst., vol. 20, no. 2, pp. 587-595, May 2005.

[7] M. Ortega-Vazquez and D. Kirschen, "Estimating the spinning reserve requirements in systems with significant wind power generation penetration," IEEE Trans. Power Syst., vol. 24, no. 1, pp. 114-123, February 2009

[8] J. Morales, A. Conejo, and J. Perez-Ruiz, "Economic valuation of reserves in power systems with high penetration of wind power,' IEEE Trans. Power Syst., vol. 24, no. 2, pp. 900-910, May 2009.

[9] T. Yong, R. Entriken, and P. Zhang, "Reserve determination for system with large wind generation," Proceedings of Power \& Energy Society General Meeting, Calgary, Canada, July 2009.

[10] F Bouffard and F. Galiana, "Security for operations planning with significant wind power generation," IEEE Trans. Power Syst. vol. 23 , no. 2, pp 306-316, May 2008.

[11] P. Ruiz, C.R. Philbrick, and P. Sauer, "Wind power day-ahead uncertainty management through stochastic unit commitment policies," Proceedings of Power Systems Conference and Exposition, Seattle, WA, March 2009.

[12] M. Matos and R. Bessa, "Setting the operating reserve using probabilistic wind power forecasts," IEEE Trans. Power Syst., vol. 26, no. 2, pp.594-603, May 2011.

[13] M. Milligan et al, "Operating Reserves and Wind Power Integration: An International Comparison", Proceedings of 9th International Workshop on Large-Scale Integration of Wind Power into Power Systems, 18-19 ${ }^{\text {th }}$ Oct, 2010, Quebec.

[14] E. Ela, B. Kirby, E. Lannoye, M. Milligan, D. Flynn, B. Zavadil, M O'Malley, "Evolution of Operating Reserve Determination in Wind Power Integration Studies," Proceedings of IEEE PES General Meeting, Minneapolis, MN, July 2010.

[15] E. Ela, M. Milligan, and B. Kirby, "Operating Reserves and Variable Generation," NREL/TP-5500-51928, August 2011.

[16] Y. Rebours et al., "A survey of frequency and voltage control ancillary services - Part I: technical features," IEEE Trans. Power Syst., vol. 22, no. 1, pp. 350-357, February 2007.

[17] CIGRE Working Group C5.06, "Ancillary services: an overview of international practices," Technical brochure number 435, October 2010 .

[18] North American Electric Reliability Corporation, "Reliability Standards for the Bulk Electric Systems of North America," June 2010 .

[19] Electric Reliability Council of Texas, "ERCOT Methodologies for Determining Ancillary Service Requirements," 2009.

[20] ENTSO. European Network of Transmission System Operators for Electricity (ENTSO-E). Operation handbook, Appendix 1, LoadFrequency Control and Performance. Available at https://www.entsoe.eu/fileadmin/user_upload/_library/publications/en tsoe/Operation_Handbook/Policy_1_final.pdf

[21] N. Nivad, G. Rosenwald and D. Chatterjee, "Ramp Capability for Load Following in MISO Markets", Market Development and Analysis, 2011. Available at https://www.misoenergy.org/_layouts/MISO/ECM/Redirect.aspx?ID= 112806

[22] A. Robitaille, et al. "Preliminary Impacts of Wind Power Integration in the Hydro-Quebec System," Wind Engineering 2012 (in press)

[23] N. Menemenlis, M. Huneault, J. Bourret, A. Robitaille, "Calculation of Balancing Reserves Incorporating Wind Power into the HydroQuébec System over the Time Horizon of 1 to 48 Hours", $8^{\text {th }}$
International Workshop on Large-Scale Integration of Wind Power into Power Systems as well as on Transmission Networks of Offshore Wind Farms, 14-15 October,2009, Bremen, Germany.

[24] N. Menemenlis, M. Huneault, A. Robitaille, "Computation of Dynamic Operating Balancing Reserve for Wind Power Integration over the Time Horizon of 1-48 Hours", $9^{\text {th }}$ International Workshop on Large-Scale Integration of Wind Power into Power Systems as well as on Transmission Networks of Offshore Wind Farms, 18-19 October,2010, Québec, Canada.

[25] M. O’Malley, G. Strbac, B. Fox, D. Flynn, R. Slark, S. Rourke, J. Sinner: "Operating reserve requirements as wind power penetration increases in the Irish electricity system", Sustainable Energy Ireland, August 2004

[26] E. Ela and B. Kirby, "ERCOT Event on February 26, 2008: Lessons Learned," NREL Technical Report, NREL/TP-500-43373, July 2008

[27] EWITS (Eastern Wind Integration and Transmission study), prepared for the National Renewable Energy Laboratory, January 2010. Available at http://www.nrel.gov/wind/systemsintegration/

[28] M. Gibescu, A. Brand, W.L. Kling "Estimation of Variability and Predictability of Large-scale Wind Energy in The Netherlands", Wind Energy 2009, vol. 12, pp. 241-260

[29] H. Holttinen, M. Milligan, B. Kirby, T. Acker, V. Neimane, T. Molinski, "Using Standard Deviation as a Measure of Increased Operational Reserve Requirement for Wind Power," Wind Engineering, 32(4), 2008, pp. 445-451.

[30] B. Lange, U. Cali, R. Jursa, R. Mackensen, K. Rohrig, and F. Schlögl, "Strategies for Balancing Wind Power in Germany", German Wind Energy Conference DEWEK 2006, Bremen, November 2006.

[31] J. Dobschinski, E. De Pascalis, A. Wessel, L. von Bremen, B. Lange, K. Rohrig, Y.-M. Saint-Drenan, "The potential of advanced shortestterm forecasts and dynamic prediction intervals for reducing the wind power induced reserve requirements. Proceedings of European Wind Energy Conference EWEC2010, 20-23rd April, 2010, Warsaw, Poland.

[32] B. Hodge, M. Milligan, "Wind Power Forecasting Error Distributions over Multiple Timescales," Presented at IEEE Power and Energy Society General Meeting, July 2011. Detroit

[33] Western Wind and Solar Integration Study, prepared for NREL by GE Energy, NREL/SR-550-47434, May 2010

[34] B.C. Ummels, M. Gibescu, E. Pelgrum, W.L. Kling, "System Integration of Large-Scale Wind Power in the Netherlands," Power Engineering Society General Meeting, 2006, Montreal.

[35] German Energy Agency (Deutsche Energie-Agentur GmbH (dena)): "dena-Netzstudie II - Integration of Renewable Energy Sources in the German Power Supply System from 2015 - 2020 with an Outlook to 2025", Berlin, November 2010

[36] Fraunhofer IWES: „Energiewirtschaftliche Bewertung von Pumpspeicherwerken und anderen Speichern im zukünftigen Stromversorgungssystem“, Kassel, 2010 (in German)

[37] O.Brückl: "Wahrscheinlichkeitstheoretische Bestimmung des Regelund Reserveleistungsbedarf in der Elektrizitätswirtschaft", $\mathrm{PhD}$ dissertation, TU München, München, 2006 (in German)

[38] J. King, B. Kirby, M. Milligan, and S. Beuning, "Operating Reserve Implication of Alternative Implementations of an Energy Imbalance Service on Wind Integration in the Western Interconnection," National Renewable Energy Laboratory, (in press)

[39] EirGrid and SONI: All island TSO facilitation of renewables studies, June 2010 Available: http://www.eirgrid.com/renewables/facilitationofrenewables/

[40] P. Meibom et al.: "Stochastic optimization model to study the operational impacts of high wind penetrations in Ireland," IEEE Trans. Power Systems, vol. 26, no. 3, pp. 1367-1379, August 2011.

[41] R.J. Bessa, M.A. Matos, I.C. Costa, L. Bremermann, I. Franchin, R. Pestana, N. Machado, H-P. Waldl, C. Wichmann, "Reserve setting and steady-state security assessment using wind power uncertainty forecast: a case study," IEEE Trans. Sustainable Energy (in review) 